\title{
Preparation and study of conductivity in lithium salt complexes of mixed MEEP : PEO polymer electrolytes
}

\author{
G SAIBABA*, D SRIKANTH ${ }^{\dagger}$ and A RAMACHANDRA REDDY ${ }^{\dagger}$ \\ Department of Physics, Railway College, Kazipet 506 003, India \\ ${ }^{\dagger}$ Department of Physics, National Institute of Technology, Warangal 506 004, India
}

MS received 3 June 2003; revised 6 September 2003

\begin{abstract}
Poly(ethylene oxide)-LiX complexes and poly[bis(methoxy ethoxy ethoxide) phosphazene]-LiX complexes of polymer thin films were prepared. Conductivity measurements were carried out and the values were found to lie between $10^{-8}$ and $1.7 \times 10^{-5}(\mathrm{~S} / \mathrm{cm})$. MEEP : LiX salts showed higher conductivity than PEOLiX salts despite lower dimensional stability. For enhancing stability and conductivity, MEEP-PEO : $(\text { LiX })_{n}$ systems were prepared and conductivity measurements carried out. Further the MEEP/PEO : $(\mathrm{LiX})_{n}$ was doped with $\mathrm{Al}_{2} \mathrm{O}_{3}$ and $\mathrm{TiO}_{2}$ nanocomposite ceramic fillers and the conductivity was studied. The conductivity vs temperature plots showed the enhancement of conductivity with $\mathrm{TiO}_{2}$ added nanocomposite ceramic fillers. The enhanced conductivity is explained on the basis of the effect of local structural modification-promoting localized amorphous region-for enhancement of the $\mathrm{Li}^{+}$ion transport.
\end{abstract}

Keywords. Complexes; conductivity; structural modification; amorphous region.

\section{Introduction}

Rechargeable solid-state Li batteries employing polymer electrolytes are being actively pursued as possible power sources for a variety of applications (Armand 1986; MacCullum and Vincent 1987). Although several theoretical models have been put forward to explain ionic motion in polymer electrolytes, present understanding of this phenomenon is rather incomplete (Papke et al 1982; Hibma 1983; Scrosati et al 2000; Chung et al 2001). A significant part of the current effort is concerned with developing mixed polymer electrolyte by using a novel class of plasticizers. Classical polymer electrolytes are composed of complexes of poly(ethylene oxide) or PEO, with Li salts (MacCullum and Vincent 1987). The low conductivity (i.e. $<10^{-7} \mathrm{ohm}^{-1} \mathrm{~cm}^{-1}$ ) of these poly[ethylene oxide] electrolytes at room temperature has limited their use in batteries operating at relatively high temperature of about $100^{\circ} \mathrm{C}$. However, PEO-LiX polymer electrolytes are affected by some problems, viz. (i) a reactivity towards the lithium metal electrode and (ii) a low conductivity at ambient temperature. Later, there have been reports of organic solvents like sulfolane (SL), propylene carbonate (PC), acetonitrile (AN) and tetrahydrofuran (THF) in $\mathrm{LiAsF}_{6}$ showing the conductivity to be around $10^{-3} \mathrm{ohm}^{-1} \mathrm{~cm}^{-1}$ at $25^{\circ} \mathrm{C}$. The conductivity of $35 \mathrm{Ec} / 30 \mathrm{Pc} /$ $25 \mathrm{PVP} / 11 \mathrm{LicF}_{3} \mathrm{SO}_{3} ; 31 \mathrm{Ec} / 26 \mathrm{Pc} / 32 \mathrm{PVP} / 11 \mathrm{LicF}_{3} \mathrm{SO}_{3} ; 54 \mathrm{Pc} /$

*Author for correspondence
35PVP/11 $\mathrm{LicF}_{3} \mathrm{SO}_{3}$ etc compositions of organic solvent and polymer electrolytes, was reported to be around $10^{-4} \mathrm{ohm}^{-1} \mathrm{~cm}^{-1}$ at $25^{\circ} \mathrm{C}$. However, little information was given concerning their compositions (Abraham 1986; Rhoo et al 1995; Yoshino et al 1996).

Complexes of certain $\mathrm{Li}$ salts and inorganic poly[bis(methoxy ethoxy ethoxide) phosphazene] named as MEEP, belong to the class of high conductivity polymer electrolytes (Blonsky et al 1984). However, MEEP-(LiX) ${ }_{n}$ polymer electrolytes have shown poor mechanical properties and hence cannot be cast as free standing thin films for electrolyte in solid state Li batteries. For enhancing the mechanical as well as dimensional stability, the MEEP$(\mathrm{LiX})_{n}$ system was significantly improved by blending them with high molecular weight of PEO. The systematic studies on these lines were reported earlier (Abraham et al 1988, 1989; Best et al 2001).

Another technique to enhance the conductivity without affecting the morphological and mechanical properties at or near ambient temperature is to add a low molecular weight organic nonaqueous solvent such as ethylene carbonate, dimethyl carbonate, etc. These liquids can be used as plasticizers to enhance the conductivity (Sheldon et al 1989; Michael et al 1997). But when the systems were added with liquid plasticizers, it loses its solid state configuration due to loss of compatibility with lithium electrodes. This represents loss of the most important feature of the polymer electrolyte. Consequently liquid plasticizers such as PEO- $(\mathrm{LiX})_{n}$ cannot be used in lithium batteries because of their limited processibility and 
high reactivity causes serious problems in terms of battery cyclability and safety. Thus work is needed to find out the proper approaches for solving or minimizing these drawbacks. In this paper, it is shown that the dispersion of selected ceramic powders in the polymer mass, produces composite PEO-MEEP : LiX polymer electrolytes which show improvement in both interfacial and transport properties as reported earlier (Weston and Steete 1982; Croce and Scrosati 1993; Borghini et al 1995).

\section{Experimental}

\subsection{Polymer film preparation}

PEO was obtained from BDH Limited (polyox WSR-301, MW $\sim 4 \times 10^{6}$ ) in powdered form and used without further purification. MEEP was synthesized according to a previously reported procedure (Allock et al 1986). The Li$\mathrm{ClO}_{4}$ and $\mathrm{LiBF}_{4}$ were obtained from Fluka, Germany and Aldrich. The samples of MEEP : $\left(\mathrm{LiClO}_{4}\right)_{n} ; \mathrm{PEO}:\left(\mathrm{LiBF}_{4}\right)_{n}$; $\mathrm{MEEP} / \mathrm{PEO}-\left(\mathrm{LiBF}_{4}\right)_{n}$ and MEEP/PEO- $\left(\mathrm{LiClO}_{4}\right)_{n}$ and $\mathrm{Al}_{2} \mathrm{O}_{3}$ and $\mathrm{TiO}_{2}$ doped composite ceramic fillers were prepared by using the usual technique (Abraham et al $1988,1989)$. Here $n=0.033,0 \cdot 07,0 \cdot 13,0 \cdot 18,0 \cdot 125$ and $0 \cdot 25$. The MEEP/PEO samples were made in the ratio $55: 45$.

Differential scanning calorimeter (DSC) experiments were conducted to estimate the degree of crystallinity in the composites. The experiments were carried out in the temperature range -93 to $160^{\circ} \mathrm{C}$ using TA instruments, DSC (model 2910) at a heating rate of $10^{\circ} \mathrm{C} / \mathrm{min}$. The procedure for estimating the degree of crystallinity in the composites is described elsewhere (Allock et al 1986).

\subsection{Conductivity measurements}

The d.c. conductivity was measured using samples of $1 \mathrm{~cm}$ diameter sandwiched between two electrodes. The samples were coated with silver paint for good electrical contact. The electrodes were sealed with glass tube and the currents were measured using Keithley electrometer by varying temperature at the rate of $100^{\circ} \mathrm{C} / \mathrm{h}$.

\section{Results and discussion}

The DSC studies of PEO show an endothermic, melting point peak at $72^{\circ} \mathrm{C}$. The MEEP did not show any DSC peak between room temperature and $150^{\circ} \mathrm{C}$, implying that the entire MEEP is completely amorphous. MEEP/PEO$(\mathrm{LiX})_{n}$ mixed electrolytes with low salt concentrations $\left(\mathrm{X}_{\mathrm{Li}^{+}}<0 \cdot 13\right)$ also showed endothermic peak around the melting point of $\mathrm{PEO}$.

The DSC traces of MEEP/PEO- $\left(\mathrm{LiBF}_{4}\right)_{0.18}$ were made from $-93^{\circ} \mathrm{C}$ to $200^{\circ} \mathrm{C}$. The endothermic heat flow vs temperature showed two peaks indicating the presence of two crystalline phases, crystalline PEO which melts at $64^{\circ} \mathrm{C}$ and a crystalline salt rich complex that melts at $137^{\circ} \mathrm{C}$. Since MEEP: $\left(\mathrm{LiBF}_{4}\right)_{n}$ does not show any thermal peak in this temperature range, the peak at $137^{\circ} \mathrm{C}$ can be ascribed to $\mathrm{LiBF}_{4}$ complexed PEO. It is concluded that the mixed MEEP/PEO- $\left(\mathrm{LiBF}_{4}\right)$ formed individual complexes of PEO: $\left(\mathrm{LiBF}_{4}\right)_{n} ; \mathrm{MEEP}:\left(\mathrm{LiBF}_{4}\right)_{n}$ semicrystalline form of MEEP/PEO: $\left(\mathrm{LiBF}_{4}\right)$ in the mixed polymer electrolyte. The endothermic peak is observed at $124^{\circ} \mathrm{C}$ in the mixed electrolyte. Similar type of behaviour was observed in the case of MEEP/PEO: $\left(\mathrm{LiClO}_{4}\right)_{n}$ system and the results are similar to those previously reported (Abraham et al 1989; Robitaille and Fauteux 1986).

MEEP/PEO : $(\mathrm{LiX})_{n}$ system containing $10 \%$ wt of $\mathrm{Al}_{2} \mathrm{O}_{3}$ and $\mathrm{TiO}_{2}$ systems also exhibit two endothermic peaks indicating the presence of two crystalline phases at $58^{\circ} \mathrm{C}$ and $133^{\circ} \mathrm{C}$. These two peaks are similar in behaviour as unplasticised samples.

The Arrhenius plots of the conductivity of MEEP:(Li$\left.\mathrm{ClO}_{4}\right)_{0.25}$; PEO : $\left(\mathrm{ClO}_{4}\right)_{0.125}$ MEEP : $\left(\mathrm{LiBF}_{4}\right)_{0.25}$ and PEO : $\left(\mathrm{LiBF}_{4}\right)_{0.125}$ are shown in figure 1. At room temperature, the PEO : $\left(\mathrm{LiClO}_{4}\right)_{n}$ and PEO : $\left(\mathrm{LiClO}_{4}\right)_{n}$ are partially crystalline, while MEEP : $\left(\mathrm{LiBF}_{4}\right)_{n}$ and MEEP : $\left(\mathrm{LiClO}_{4}\right)_{n}$ com-

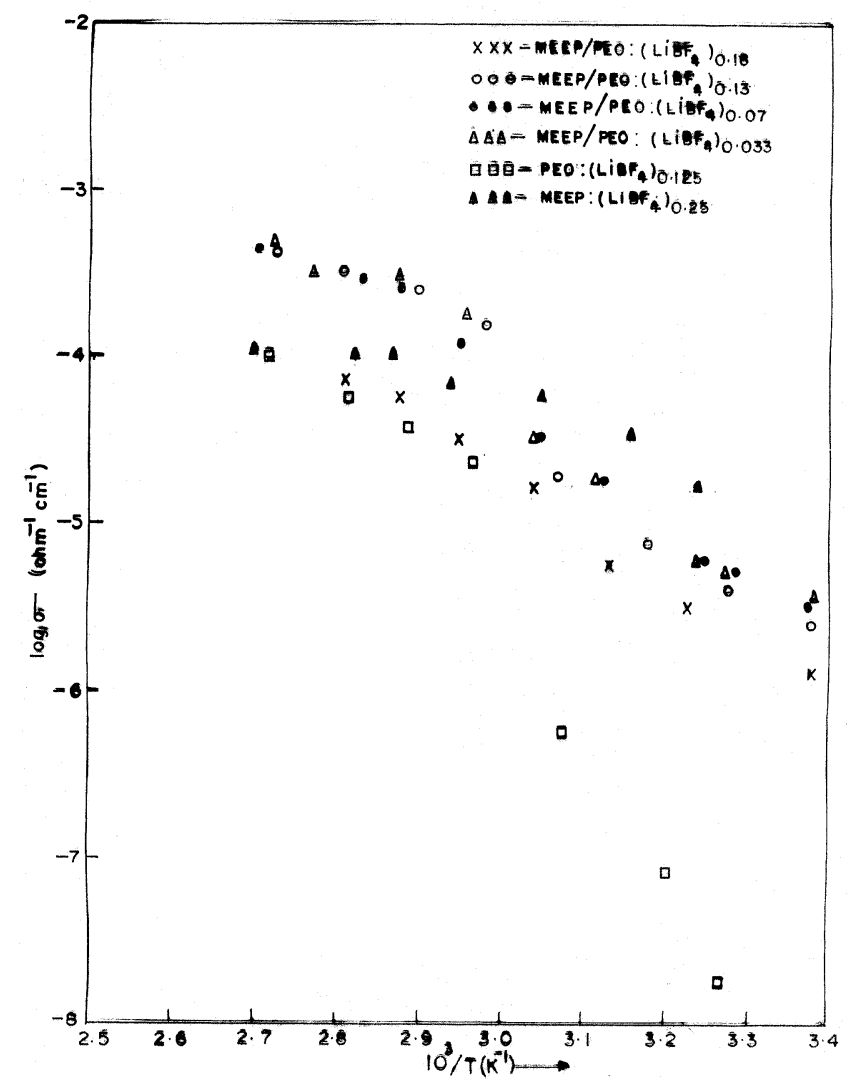

Figure 1. Conductivity vs temperature plots of MEEP/PEO : $\left(\mathrm{LiBF}_{4}\right)_{n}$. 
plexes are fully amorphous. From the plots, it is observed that the conductivity of Arrhenius plots of MEEP:(Li$\left.\mathrm{ClO}_{4}\right)_{0.25}$ and MEEP: $\left(\mathrm{LiBF}_{4}\right)_{0.25}$ exhibit higher conductivity than the PEO: $(\mathrm{LiX})_{n}$ complexes. But above $60^{\circ} \mathrm{C}$ the conductivity increases abruptly in PEO- $(\mathrm{LiX})_{n}$ and shows rather similar behaviour as that of MEEP: $(\mathrm{LiX})_{n}$. The Arrhenius plots for PEO:MEEP and MEEP/PEO : $\mathrm{LiBF}_{4}$ where $n=0.033,0 \cdot 07,0 \cdot 125,0 \cdot 13,0.18$ and 0.25 are shown in figure 2 . The Arrhenius plots of comparative studies of other compositions are shown in figure 3 . The Arrhenius plots of MEEP/PEO: $\left(\mathrm{LiClO}_{4}\right)_{0.07}$ and MEEP/ PEO : $\left(\mathrm{LiClO}_{4}\right)_{0.25}$ show higher and similar conductivity although the mechanical properties of MEEP: $\left(\mathrm{LiClO}_{4}\right)_{0.25}$ are poor.

Arrhenius plots of MEEP/PEO: $\left(\mathrm{LiClO}_{4}\right)_{0.07}, \mathrm{MEEP} /$ PEO : $\left(\mathrm{LiBF}_{4}\right)_{0.07}, \mathrm{MEEP} / \mathrm{PEO}:\left(\mathrm{LiBF}_{4}\right)_{0.07}+10 \%$ wt of $\mathrm{Al}_{2} \mathrm{O}_{3}$ and MEEP/PEO : $\left(\mathrm{LiBF}_{4}\right)_{0.07}+10 \%$ wt of $\mathrm{TiO}_{2}$ are respectively shown in figure 3 . The MEEP/PEO : $\left(\mathrm{LiBF}_{4}\right)_{0.07}+$ $10 \%$ wt of $\mathrm{TiO}_{2}$ show higher conductivity than other composites.

The comparison studies on 55\%-45\% w/o MEEP : PEO $(\mathrm{LiX})_{n}$ mixed electrolytes MEEP : $(\mathrm{LiX})_{n}$ and PEO $(\mathrm{LiX})_{n}$ of Arrhenius plots are shown in figures 2 and 3, respectively. From the plots it is clear that MEEP: $\left(\mathrm{LiClO}_{4}\right)_{0.25}$ and MEEP : $\left(\mathrm{LiClO}_{4}\right)_{0.07}$ exhibit similar conductivity than

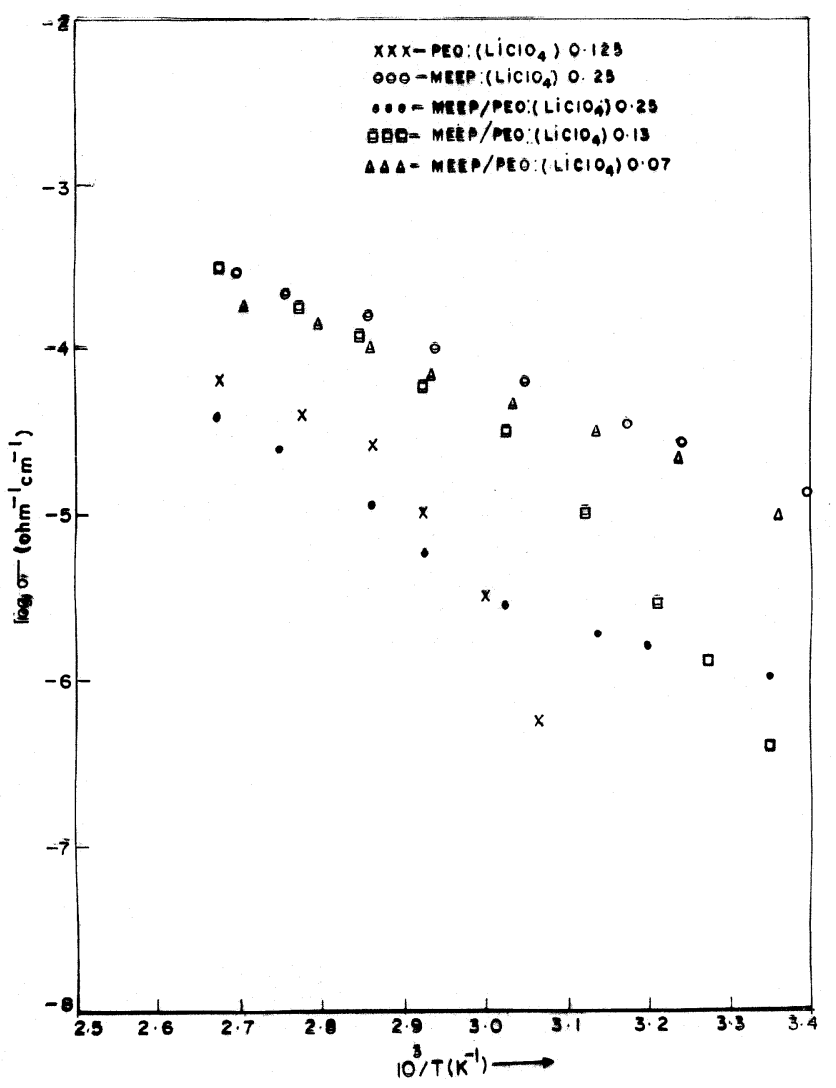

Figure 2. Conductivity vs temperature plots of MEEP/PEO : $\left(\mathrm{LiClO}_{4}\right)_{n}$. other samples. In other compositions also MEEP: $\left(\mathrm{LiBF}_{4}\right)_{0.25}$ and MEEP/PEO: $\left(\mathrm{LiBF}_{4}\right)_{0.07}$ exhibit similar higher conductivity. The conduction mechanism in mixed polymer electrolytes of MEEP/PEO : $(\mathrm{LiX})_{n}$ was explained earlier by various investigators (Abraham et al 1988, 1989; Abraham and Alamgiri 1991).

In an attempt to produce ceramic powders of nanoparticle size, solid state MEEP/PEO: $(\mathrm{LiX})_{n}$ mixed polymer composite electrolyte was used. This electrolyte works in the temperature range $30-80^{\circ} \mathrm{C}$ with better mechanical stability, high ionic conductivity and good interfacial characteristics as reported earlier (Weston and Steete 1982; Croce and Scrosati 1993; Borghini et al 1995). From the review of the work, it is inferred that this method was never been used for promoting low temperature conductivity in mixed polymer electrolytes. So in the present investigation, an attempt has been made to study the effect of $\mathrm{Al}_{2} \mathrm{O}_{3}$ and $\mathrm{TiO}_{2}$ of nanocomposite ceramic fillers in $\mathrm{MEEP} / \mathrm{PEO}:(\mathrm{LiX})_{n}$ system and the corresponding activation energy values are calculated and shown in table 1. The Arrhenius plots of MEEP/PEO : $\left(\mathrm{LiClO}_{4}\right)_{0.07}, \mathrm{MEEP} /$ PEO : $\left(\mathrm{LiBF}_{4}\right)_{0.07}, \mathrm{MEEP} / \mathrm{PEO}:\left(\mathrm{LiBF}_{4}\right)+10 \%$ wt of $\mathrm{Al}_{2} \mathrm{O}_{3}$ and MEEP/PEO: $\left(\mathrm{LiBF}_{4}\right)+10 \%$ wt of $\mathrm{TiO}_{2}$ shows that MEEP/PEO : $\left(\mathrm{LiBF}_{4}\right)_{0.07}+10 \%$ wt of $\mathrm{TiO}_{2}$ has higher conductivity than other systems. The heating scan of the ce-

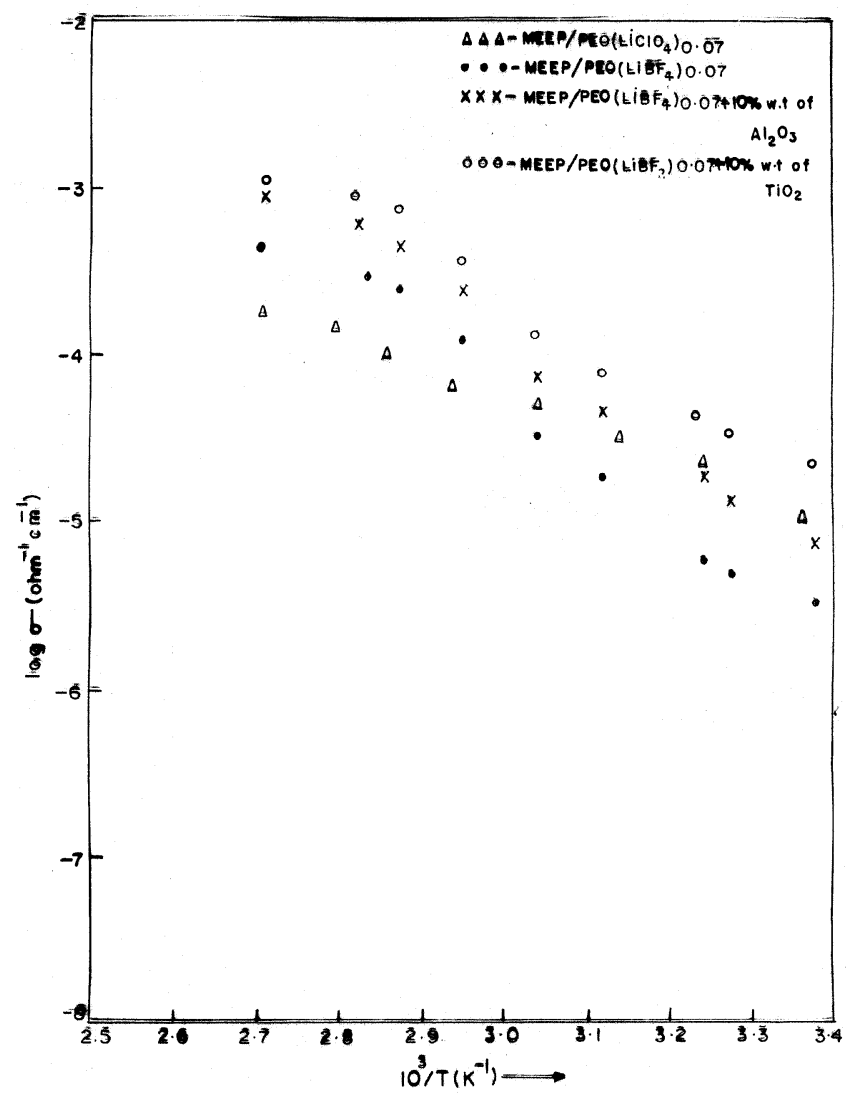

Figure 3. Arrhenius plots of MEEP: $\left(\mathrm{LiClO}_{4}\right)_{0.07}$, MEEP/ PEO : $\left(\mathrm{LiBF}_{4}\right)_{0.07}, \mathrm{MEEP} / \mathrm{PEO}:\left(\mathrm{LiBF}_{4}\right)_{0.07}+10 \%$ wt of $\mathrm{TiO}_{2}$ and MEEP/PEO : $\left(\mathrm{LiBF}_{4}\right)_{0.07}+10 \%$ wt of $\mathrm{Al}_{2} \mathrm{O}_{3}$. 
Table 1. The activation energy values of different polymer electrolytes.

\begin{tabular}{|c|c|c|}
\hline \multirow[b]{2}{*}{ System } & \multicolumn{2}{|c|}{$\begin{array}{c}\text { Corresponding activation } \\
\text { energies }(\mathrm{eV})\end{array}$} \\
\hline & at $40^{\circ} \mathrm{C}$ & at $70^{\circ} \mathrm{C}$ \\
\hline PEO : $\left(\mathrm{LiBF}_{4}\right)_{0.125}$ & $0 \cdot 3114$ & 0.6503 \\
\hline MEEP/PEO : $\left(\mathrm{LiBF}_{4}\right)_{0.18}$ & 0.5356 & 0.0300 \\
\hline MEEP/PEO : $\left(\mathrm{LiBF}_{4}\right)_{0.13}$ & 0.5892 & 1.707 \\
\hline MEEP/PEO : $\left(\mathrm{LiBF}_{4}\right)_{0.07}$ & $0 \cdot 546$ & $0 \cdot 273$ \\
\hline MEEP/PEO : $\left(\mathrm{LiBF}_{4}\right)_{0.033}$ & 0.4553 & $0 \cdot 585$ \\
\hline MEEP/PEO : $\left(\mathrm{LiBF}_{4}\right)_{0.025}$ & 0.7285 & $1 \cdot 0408$ \\
\hline MEEP/PEO : $\left(\mathrm{LiClO}_{4}\right)_{0 \cdot 13}$ & 1.0927 & 0.4202 \\
\hline MEEP/PEO : $\left(\mathrm{LiClO}_{4}\right)_{0.25}$ & $0 \cdot 3035$ & 0.4202 \\
\hline PEO : $\left(\mathrm{LiClO}_{4}\right)_{0.125}$ & $1 \cdot 5685$ & $0 \cdot 4047$ \\
\hline MEEP/PEO : $\left(\mathrm{LiClO}_{4}\right)_{0.07}$ & $0 \cdot 3749$ & 1.707 \\
\hline MEEP : $\left(\mathrm{LiClO}_{4}\right)_{0.25}$ & 0.4138 & \\
\hline $\begin{array}{l}\text { MEEP/PEO : }\left(\mathrm{LiBF}_{4}\right)_{0 \cdot 17}+ \\
10 \% \text { wt of } \mathrm{Al}_{2} \mathrm{O}_{3}\end{array}$ & $0 \cdot 525$ & 0.607 \\
\hline MEEP/PEO : $\left(\mathrm{LiClO}_{4}\right)_{0.07}$ & $0 \cdot 3749$ & $0 \cdot 476$ \\
\hline $\begin{array}{l}\mathrm{MEEP} / \mathrm{PEO}:\left(\mathrm{LiBF}_{2}\right)_{0.07}+ \\
10 \% \text { wt of } \mathrm{TiO}_{2}\end{array}$ & $0 \cdot 5098$ & $0 \cdot 2731$ \\
\hline
\end{tabular}

ramic free electrolyte and dispersion of nanocomposite ceramic did not show any break and is accompanied by increase in conductivity of dispersion ceramic fillers mixed electrolyte. This implies that the semicrystalline nature of PEO is reduced and it is in the form of amorphous state. This was already confirmed in DSC studies (Abraham et al 1989; Binod Kumar et al 1999).

From the DSC data the corresponding endothermic transition values are evaluated and the values are compared with the transition temperature of conductivity plots (with respect to change in slope value). The values of endothermic transition temperature and corresponding temperature of slope changes are shown below.

In case of PEO: $\left(\mathrm{LiBF}_{4}\right)_{n}$, the DSC value is $65^{\circ} \mathrm{C}$ and $67^{\circ} \mathrm{C}$ from the conductivity plot. In MEEP/PEO : $\left(\mathrm{LiBF}_{4}\right)_{n}$, DSC value is $58^{\circ} \mathrm{C}$ and $54^{\circ} \mathrm{C}$ from the conductivity plot. Similarly in PEO: $\left(\mathrm{LiClO}_{4}\right)_{n}$ the endothermic transition value is $64^{\circ} \mathrm{C}$ and from conductivity plot it is $62^{\circ} \mathrm{C}$. In MEEP/PEO : $\left(\mathrm{LiClO}_{4}\right)_{n}$, the DSC peak is at $64^{\circ} \mathrm{C}$ and from conductivity plot it is $58^{\circ} \mathrm{C}$. From the above data it is clear that the endothermic transition values are nearly correlating with the conductivity plots change in slope values.

One possibility for the mechanism of enhanced conductivity in MEEP/PEO ( $\mathrm{LiX})_{n}$ containing nanocomposite ceramic fillers is as follows. When the MEEP/PEO mixed electrolytes was doped with $\mathrm{LiBF}_{4}$ and $\mathrm{LiClO}_{4}$, it favoured formation of complexes with ether or oxygen in PEO or in MEEP. In case of ceramic free mixed electrolytes it favoured to form more transient cross links with dimensional stable morphology due to large cation-anion association effects (Abraham 1993). Due to increase in transient cross links the mobility of $\mathrm{Li}^{+}$increases so that conductivity is increased in mixed polymer electrolytes. When the systems were dispersed with nanocomposite ceramic fillers like $\mathrm{Al}_{2} \mathrm{O}_{3}$ and $\mathrm{TiO}_{2}$ with $10 \% \mathrm{wt}$, there is a possibility that conductivity enhancement is greater in $\mathrm{TiO}_{2}$ than $\mathrm{Al}_{2} \mathrm{O}_{3}$ due to fast ion transport. This could have been related to dilution effect promoted by an excess of liquid adsorbed by the ceramic during casting and released in the heating scan. For this purpose, the samples were initially heated to $130^{\circ} \mathrm{C}$ after preparation. Due to this the crystalline phase is converted to amorphous phase. Simultaneously there was an enhancement of mechanical properties in these systems (Saibaba 2003).

These interactions originate a series of processes which work together to increase the fraction of free ions and to enhance their mobility. In fact, it is reasonable to assume that the acid sites on the surface of the ceramic particles may compete with acid lithium cations to form complexes with the basic oxygen [ether] on the MEEP and PEO chains. Thus the ceramics may act as cross linking centres for PEO and MEEP segments; thereby lowering the reorganization tendency of the polymer chain and promoting preferred $\mathrm{Li}^{+}$transport routes at the boundaries of the ceramic particles. Under these conditions, a consistent enhancement of the cation transference number is expected (Evans et al 1987; Croce and Scrosati 1993).

The results obtained here on MEEP/PEO: $\left(\mathrm{LiBF}_{4}\right)_{0.07}+$ $10 \%$ wt of $\mathrm{TiO}_{2}$ show higher conductivity than MEEP/ PEO : $\left(\mathrm{LiBF}_{4}\right)_{0.07}+10 \%$ wt of $\mathrm{Al}_{2} \mathrm{O}_{3}$. Further the conductivity of fillers of $\mathrm{Al}_{2} \mathrm{O}_{3}$ of mixed polymer electrolyte had pronounced towards temperature axes. That means the MEEP/PEO : $\left(\mathrm{LiBF}_{4}\right)_{0.07}+10 \%$ wt of $\mathrm{Al}_{2} \mathrm{O}_{3}$ might get some disturbance in configuration [mechanical properties]. For this, further investigation is required.

We believe that a proper choice of the type and morphology of the ceramic filler could optimize the conduction. This might lead to the development of mixed polymer electrolytes having a true solid state configuration with high conductivity and high interfacial stability, which are ideal for rechargeable batteries (Scrosati 1995).

\section{Acknowledgements}

One of the authors (GS) is thankful to CPO; Sr. DPO(SC) of South Central Railway, Hyderabad, for constant encouragement. He also thanks Prof. K Narsimha Reddy, Prof. M Narsimhachary and Prof. U V Subba Rao, Department of Physics, Osmania University, Hyderabad, for useful comments and suggestions.

\section{References}

Abraham K M 1986 Applications of electro active polymers (Highly conductive polymer electrolytes) (London: Chapman \& Hall) pp 75-112

Abraham K M and Alamgiri M 1991 Chem. Mater. 3339

Abraham K M, Alamgiri M and Perrotic S J 1988 J. Electrochem. Soc. 135535 
Abraham K M, Alamgiri M and Reynolds R K 1989 J. Electrochem. Soc. 1363576

Allock H R, Austin P E, Sisko J T, Blonsky P M and Shriver D F 1986 Macro Molecules 191508

Armand M B 1986 Ann. Rev. Mater. Sci. 16245

Best A S et al 2001 Macro Molecules 344549

Binod Kumar B, Lawrence G and Scanlan 1999 Solid State Ionics $\mathbf{1 2 4} 239$

Blonsky P M, Shriver D F, Austing P F and Allcock H R 1984 J. Am. Chem. Soc. 1066854

Borghini N, Mastragostino M C, Passerini M and Scrosati B 1995 J. Electrochem. Soc. 1422118

Chung S H, Wang Y, Persi L, Croce F, Greenbraum S G, Scrosati B and Plichta E 2001 J. Power Sources 97-98 644

Croce F and Scrosati B 1993 J. Power Sources 439

Evans J, Vincent C A and Bruce P G 1987 Polymer 282325

Florianczy K, Such K, Wiecsorek W and Wasiucionek N 1991 Polymer 323422

Hibma T 1983 Solid State Ionics 9-10 1101
MacCullum J R and Vincent C A (eds) 1987 Polymer electrolyte reviews (London: Elsevier Pub. Co.)

Michael M S, Jacob M ME, Prabaharan S R S and Radhakrishna S 1997 Solid State Ionics 98167

Papke B L, Ratner M A and Shriver D F 1982 J. Electrochem. Soc. 1291694

Robitaille C D and Fauteux D 1986 J. Electrochem. Soc. 133 316

Rhoo H J, Kim H T, Park J M and Hwang T S 1995 Electrochim. Acta 40991

Saibaba G 2003 Solid State Ionics (communicated)

Scrosati B 1995 Nature 373557

Scrosati B, Croicef F and Persi L 2000 J. Electrochem. Soc. 5 1718

Sheldon M H, Glasse M D, Latham R F and Linford R G 1989 Solid State Ionics 34135

Weston J E and Steete B C H 1982 Solid State Ionics 775

Yoshino K, Yim X H, Tada K, Kawrahigost T and Kato H 1996 Trans. Dielect. \& Electr. Insul. 3331 